\title{
ALTERED AUTONOMIC BALANCE IN NORMAL TENSION GLAUCOMA
}

\author{
ARIJITA BANERJEE*, INDU KHURANA \\ Department of Physiology, Pandit Bhagwat Dayal Sharma Post Graduate Institute of Medical Sciences, Rohtak, Haryana, India. \\ Email: b.arijita@gmail.com
}

Received: 01 September 2016, Revised and Accepted: 18 October 2016

ABSTRACT

Objective: To study autonomic imbalance if any in normal tension glaucoma (NTG)patients by heart rate variability (HRV)and head-up tilt (HUT)test.

Methods: The study subjects of age between 45 and 65 years of either sex comprised 20 patients with NTG (Group II)and 20 age- and sex-matched healthy controls (Group I). Different variables of time and frequency domain of HRV were analyzed at rest, during HUT and the recovery period.

Results: Highly significant decrease in value of root mean square successive difference observed in Group II ( $p<0.000$ )in comparison to controls. The high-frequency variables ( HF $[\mathrm{nu}]$ and $\mathrm{HF}\left[\mathrm{ms}^{2}\right]$ ) were significantly less $(\mathrm{p}<0.000)$ and low frequency $(\mathrm{LF}) / \mathrm{HF}$ ratio was significantly high $(\mathrm{p}<0.000)$ in Group II.

Conclusion: During stress test, i.e., HUT there was the greater withdrawal of parasympathetic input to heart; hence, there was relatively over sympathetic activity due to sympatho-vagal imbalance.

Keywords: Stress test, Sympatho-vagal imbalance, Autonomic function test.

(C) 2017 The Authors. Published by Innovare Academic Sciences Pvt Ltd. This is an open access article under the CC BY license (http://creativecommons. org/licenses/by/4. 0/) DOI: http://dx.doi.org/10.22159/ajpcr.2017.v10i2.15001

\section{INTRODUCTION}

Glaucoma is broadly divided into two subcategories, namely, high tension or primary open angle glaucoma (POAG), in which intraocular pressure (IOP) is elevated ( $>21 \mathrm{mmHg}$ ) and normal tension glaucoma (NTG), in which IOP is within normal range $(10-21 \mathrm{mmHg})$ along with visual field defects and associated morphological changes in optic disc. With regard to vascular risk, stronger associations between the presence of vascular factors such as vasospasm, vascular dysregulation, and hypotension have been made with NTG in comparison to POAG, and rather NTG patients have also been found to show a more frequency of migraine and Raynaud's phenomenon [1-3].

The possibility that POAG and NTG representing two distinct clinical entities can, therefore, not be ruled out, however, much of the literature is conflicting making it difficult to draw any firm conclusions. The disturbed vascular function has been recognized with regard to glaucoma, with authors as early as 1925 proposing an alternative vascular theory of glaucoma development along with the involvement of circulatory disturbances and vascular dysregulation. Autoregulation of ocular blood flow is a complex process involving the autonomic control, systemic blood pressure (myogenic control), circulating hormones (humoral control), and the endothelium. Abnormalities such as endothelial dysfunction, vasospastic syndrome, and autonomic dysfunctions have been implicated in the development of autoregulatory abnormalities in glaucoma. Indeed, few studies have provided evidence of disturbed autoregulation in glaucoma patients not only at the ocular level but also at the systemic level seen in those with progressive glaucoma [4-8].

Assessment of heart rate variability (HRV) can provide an indirect assessment of the autonomic control of the heart, commonly used for the investigation of normal physiology and pathological conditions. Heart rate response to head-up tilt (HUT) is a useful tool in the diagnosis of autonomic dysfunctions. Heart rate rises immediately due to withdrawal of parasympathetic activity. The hemodynamic response to postural challenge during HUT table test has emerged as an index test for cardiovascular autonomic activity. The HUT test produces predictable set of circulatory adjustments on change of posture (lying to standing) to overpower the effect of gravity. The immediate cardiovascular response resulting due to passive HUT signifies the function of cardiopulmonary and arterial baroreceptors [9-12].

Therefore, in the present study, we aimed to assess the sympatho-vagal imbalance using HUT with HRV in patients with NTG.

\section{METHODS}

The study sample of age between 45 and 65 years of either sex comprised two groups: Group I - 20 age- and sex-matched healthy controls and Group II - 20 patients with NTG. The study was approved by the Institutional Ethics Committee. Written consent was taken and the whole procedure was explained in detail to each subject in his/her own language. Each subject had undergone a complete ophthalmological examination in glaucoma clinic, IOP measurement with Goldmann applanation tonometer.

\section{Inclusion criteria for Group II (NTG)}

IOP 10-21 mmHg without treatment, optic disc changes suggestive of glaucomatous damage including one or more of these signs: Neuroretinal rim notching, optic disc excavation, vertical or horizontal cup to disk ratio $>0.5$ and peripapillary splinter hemorrhages, visual field outside normal limits on Humphrey automated perimetry on three perimetry readings, and all angles $\left(360^{\circ}\right)$ open on gonioscopy.

\section{Exclusion criteria}

Patients with secondary causes of glaucoma, hazy media, optic neuritis, any disease involving the macula, retina, or visual pathway, high myopia ( $>6$ dioptre), previous intraocular surgery and on drugs known to cause optic neuropathy. Patients with diabetes mellitus and hypertension.

\section{Apparatus used}

Powerlab26T Polyrite D system was used for recording HRV. For HUT test, a wooden tilt table was used to avoid any electromagnetic disturbances. The table was prepared especially for manual tilting from horizontal position to $90^{\circ}$ upright. 


\section{Basal HRV}

The subject was asked to lie down on the tilt table. Then, three disposable pregelled electrodes were attached on left arm, right arm, and left leg. Basal recording of electrocardiogram (lead II) was taken for 5 minutes, and different variables of time and frequency domain were analyzed.

\section{Head-up tilt test}

Subjects were asked to comfortably restrain on a tilt table in horizontal position with foot plate support; then, the table was manually tilted to $70^{\circ}$ head up position for 2 minutes. HRV was recorded during HUT. Then, tilt table was brought back to horizontal position and HRV was recorded after 5 minutes (recovery period).

The data obtained were statistically analyzed using SPSS (version 20). HRV of Group I (healthy controls) was compared with Group II (NTG) by unpaired Student's t-test. Two-tailed significance value was set at 0.05 .

\section{RESULTS}

Basal HRV did not show any statistical differences between two groups. A highly significant decrease in root mean square successive difference (RMSSD) observed in Group II $(\mathrm{p}<0.000)$ as compared to control group. The decreased values of time domain variables signify decreased vagal activity due to greater withdrawal of vagal tone and relative increase in sympathetic activity (Fig. 1).

Highly significant decrease in values of both high and low frequency (LF) variables observed in both Group II as compared to Group I. However, a highly significant rise in LF/HF has been observed in Group II as compared to control group further indicating a greater withdrawal of vagal tone during HUT test (Table 1, Figs. 2 and 3).

Significant low values of LF and high frequency (HF) variables were observed in Group II. However, a highly significant difference has been observed in Group II (NTG) as compared to control group, and value of $\mathrm{LF} / \mathrm{HF}$ ratio was significantly high in Group II.

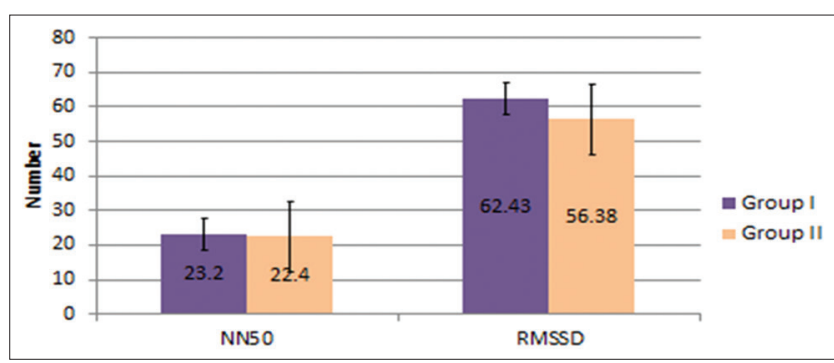

Fig. 1: Comparison of time domain variables (NN50 and root mean square successive difference) during head-up tilt

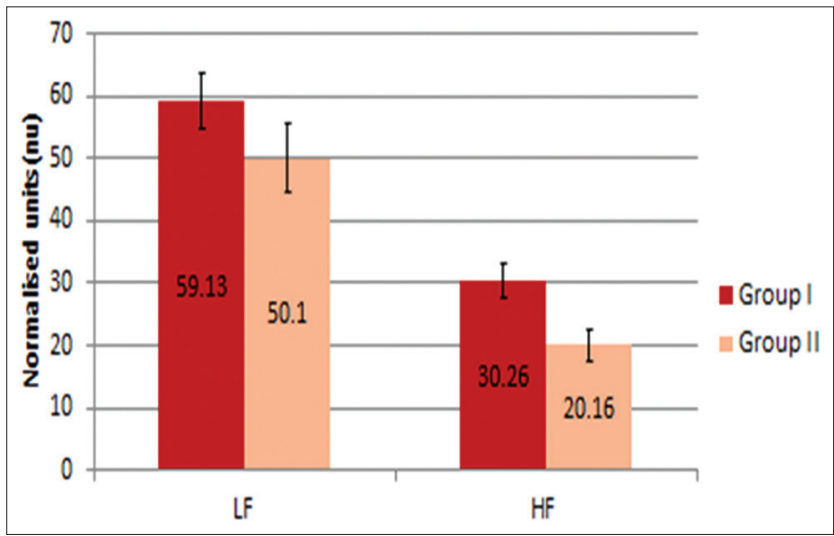

Fig. 2: Comparison of frequency domain variables left frequency and high frequency (nu) during head-up tilt
The findings of frequency domain variables of HRV during the recovery phase of HUT were indication of delayed recovery from stress test due to sympatho-vagal imbalance mainly due to parasympathetic withdrawal (Fig. 4).

\section{DISCUSSION}

HUT test is an important autonomic function test to assess sympathetic activity. The normal response is increased sympathetic activity to overpower the effect of gravity. Highly significant decrease in value of RMSSD observed in NTG group $(\mathrm{p}<0.000)$ in comparison to controls. The above findings of time domain variables of HRV in the prospective study are in accordance with studies by Sharma et al. and Brown et al. [13,14]. Similarly, the HF variables (HF [nu]and $\mathrm{HF}\left[\mathrm{ms}^{2}\right]$ ) were significantly less $(\mathrm{p}<0.000)$, and LF/HF ratio was significantly high $(\mathrm{p}<0.000)$ in Group II as compared to Group I. The HRV analysis of frequency domain variables was in accordance with the study. Kouakam et al. who analyzed the HRV response to orthostatic stress in patients with unexplained syncope during $60^{\circ} \mathrm{HUT}$ and observed LF/HF ratio was correlated with HUT. Since LF (nu) the marker of sympathetic activity, HF (nu) the marker of parasympathetic activity, therefore, during HUT significant less increase in LF band variables and less value of $\mathrm{HF}$ variables in glaucoma patients indicated less increase in sympathetic activity as well as decrease in parasympathetic activity [15]

Table 1: Frequency domain variables in Group I and II during HUT test

\begin{tabular}{llll}
\hline Parameter & Group I Mean \pm SD & Group II Mean \pm SD & p value \\
\hline LF $(\mathrm{nu})$ & $59.13 \pm 4.41$ & $50.1 \pm 5.34$ & $<0.000^{* * *}$ \\
LF $\left(\mathrm{ms}^{2}\right)$ & $684.36 \pm 63.98$ & $433.8 \pm 61.24$ & $<0.000^{* * *}$ \\
HF $(\mathrm{nu})$ & $30.26 \pm 2.79$ & $20.16 \pm 2.53$ & $<0.000^{* * *}$ \\
HF $\left(\mathrm{ms}^{2}\right)$ & $345.45 \pm 4.38$ & $175.94 \pm 34.48$ & $<0.000^{* * *}$ \\
LF $/ \mathrm{HF}$ & $1.97 \pm 0.25$ & $2.51 \pm 0.31$ & $<0.000^{* * *}$ \\
\hline
\end{tabular}

${ }^{* * *} \mathrm{p}<0.000$ very high significant. SD: Standard deviation, LF: Left frequency, HF: High frequency, HUT: Head-up tilt

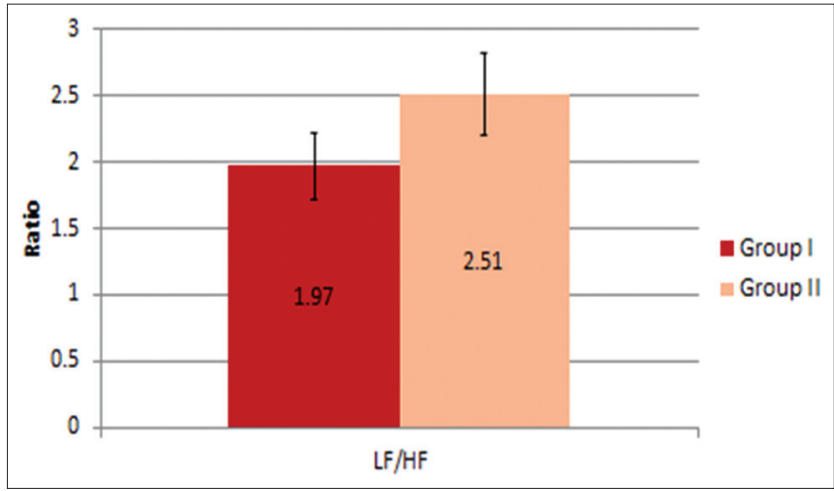

Fig. 3: Comparison of left frequency/high frequency during head-up tilt

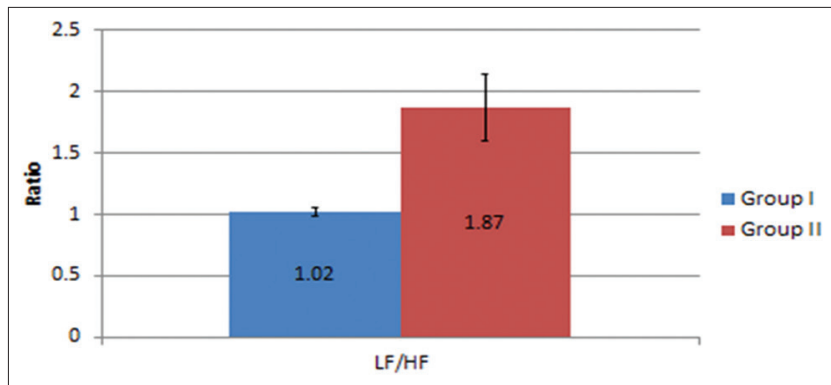

Fig. 4: Comparison of left frequency/high-frequency ratio during head-up tilt 
From these observations, during HUT, it can be concluded that in glaucoma patients, there is greater withdrawal of parasympathetic activity along with less increase in sympathetic activity. Significantly raised values of LF/HF ratio also suggestive of altered sympatho-vagal balance.

\section{CONCLUSION}

The above findings of HRV in this study further suggested greater withdrawal of vagal tone, and persistently overdrive of sympathetic activity due to sympatho-vagal imbalance, resulting delayed recovery from stress. The results and discussion of HRV analysis during provocative test concluded that autonomic imbalance was present in patients with NTG.

\section{LIMITATIONS}

As selection of glaucoma patients (NTG) was based on clinical levels of mean IOP above or below $21 \mathrm{mmHg}$, it is possible that certain degree of overlap may exist.

\section{REFERENCES}

1. Leske MC. Open-angle glaucoma - An epidemiologic overview. Ophthalmic Epidemiol 2007;14(4):166-72.

2. Kumarswamy NA, Lam FS, Wang AL, Theoharides TC. Glaucoma: Current and developing concepts for inflammation, pathogenesis and treatment. Eur J Inflamm 2006;4(3):129-37.

3. Shields MB. Textbook of Glaucoma. 3rd ed. Baltimore: Williams and Wilkins, Lippincott; 1984.

4. Flammer J, Pache M, Resink T. Vasospasm, its role in the pathogenesis of diseases with particular reference to the eye. Prog Retin
Eye Res 2001;20(3):319-49.

5. Flammer J, Mozaffarieh M. Autoregulation, a balancing act between supply and demand. Can J Ophthalmol 2008;43(3):317-21.

6. Gasser P. Ocular vasospasm: A risk factor in the pathogenesis of low-tension glaucoma. Int Ophthalmol 1989;13(4):281-90.

7. Gugleta K, Orgül S, Hasler P, Flammer J. Circulatory response to blood gas perturbations in vasospasm. Invest Ophthalmol Vis Sci 2005;46(9):3288-94

8. Nicolela MT, Ferrier SN, Morrison CA, Archibald ML, LeVatte TL, Wallace $\mathrm{K}$, et al. Effects of cold-induced vasospasm in glaucoma: The role of endothelin-1. Invest Ophthalmol Vis Sci 2003;44(6):2565-72.

9. Pagani M, Lombardi F, Guzzetti S, Rimoldi O, Furlan R, Pizzinelli P, et al. Power spectral analysis of heart rate and arterial pressure variabilities as a marker of sympatho-vagal interaction in man and conscious dog. Circ Res 1986;59(2):178-93.

10. Goldberger JJ. Sympathovagal balance: How should we measure it? Am J Physiol 1999;276(4 Pt 2):H1273-80.

11. Kenny RA, Ingram A, Bayliss J, Sutton R. Head-up tilt: A useful test for investigating unexplained syncope. Lancet 1986;1(8494):1352-5.

12. Gherghel D, Hosking SL, Armstrong R, Cunliffe IA. Autonomic dysfunction in unselected and untreated primary open angle glaucoma patients: A pilot study. Ophthalmic Physiol Opt 2007;27(4):336-41.

13. Sharma P, Paudel BH, Singh PN, Limbu P. Heart rate variability: Response to graded head up tilt in healthy men. Kathmandu Univ Med J (KUMJ)2009;7(27):252-7.

14. Brown SJ, Raman A, Barnes MJ, Mündel T. Autonomic cardiovascular response to acute hypoxia and passive head-up tilting in humans. Eur J Appl Physiol 2013;113(7):1731-6.

15. Kouakam C, Lacroix D, Zghal N, Logier R, Klug D, Le Franc P, et al. Inadequate sympathovagal balance in response to orthostatism in patients with unexplained syncope and a positive head up tilt test. Heart $1999 ; 82(3): 312-8$ 